Article

\title{
Effect of Particle Sizes on the Physical and Mechanical Properties of Briquettes
}

\author{
Longlong Pang, Yuzhong Yang *, Liyun Wu, Fei Wang and Han Meng \\ School of Energy Science and Engineering, Henan Polytechnic University, Jiaozuo 454003, Henan, China \\ * Correspondence: jityyz@hpu.edu.cn; Tel.: +86-039-1398-7959
}

Received: 21 August 2019; Accepted: 18 September 2019; Published: 23 September 2019

\begin{abstract}
The particle size of coal particles is an important factor affecting the physical and mechanical properties of coal. In this study, uniaxial and triaxial compression tests were conducted to investigate the effects of coal particle size on the physical and mechanical properties of briquettes and their impact mechanism using a rock mechanics test-150B servo system (RMT-150B). The results showed that the uniaxial compression strength, elastic modulus and deformation modulus of briquettes increase when particle size is decreased. The deformation characteristics of the briquettes directly prepared by raw tectonic coal were similar to those of coal specimens with a particle size of $0.18-0.25 \mathrm{~mm}$. The cohesion and strength of coal specimens increased when particle size was decreased, and the plastic deformation capacity decreased when particle size was decreased, showing a strong correlation. The $\mathrm{f} \mathrm{briquette} \mathrm{directly} \mathrm{prepared} \mathrm{by} \mathrm{the} \mathrm{raw} \mathrm{tectonic} \mathrm{coal} \mathrm{had} \mathrm{a} \mathrm{strength} \mathrm{between} \mathrm{that} \mathrm{of} \mathrm{coal} \mathrm{specimens}$ with a particle size of $2-6 \mathrm{~mm}$ and those with a particle size of $0.18-0.25 \mathrm{~mm}$. The mechanical properties of briquettes mainly depend on the meshing force between the coal particles. The smaller the particles, the greater the mechanical meshing force. The "floating particles", generated in the voids between coal particles during the preparation process, are a significant factor affecting the plasticity characteristics. The research results may be used as a basic reference in the study of the mechanical properties of tectonic coal, gas migration and coal and gas outburst mechanisms.
\end{abstract}

Keywords: briquette; particle size; coal and gas outburst; physical and mechanical property; floating particles

\section{Introduction}

A coal and gas outburst is a serious power disaster in coal mining, and can cause a large number of casualties and property losses. At present, China is the country with the highest risk of coal and gas outburst accidents in the world [1,2]. The mechanism of coal and gas outbursts has not been unified, but most scholars believe that coal and gas outbursts are the result of the combined effects of three major factors: ground stress, gas and the physical and mechanical properties of coal [3-8]. An unfavorable combination of these factors with mining methods can be a recipe for disaster if not recognized at an early stage of mine development [6]. In general, coal seams that are prone to outburst are subject to historical tectonic movement, resulting in the development of tectonic coal [9-11]. This type of coal is composed of coal particles of different sizes, its structure is loosened and broken and its macroscopic strength is extremely low, making coal and gas outbursts more likely to occur [12-15]. After the occurrence of a coal and gas outburst, the particle size of coal appears to be sorted; therefore, assessments of coal and gas outbursts must be treated with caution in view of particle size [6,7].

In order to reveal the mechanisms behind coal and gas outbursts, tectonic coal can be reconstructed and represented by briquettes for laboratory research according to the structure and cohesive mechanical characteristics of tectonic coal. Sobczyk et al. $[16,17]$ conducted a laboratory study on the effects of different types of gases $\left(\mathrm{CO}_{2}, \mathrm{~N}_{2}\right.$ and $\left.\mathrm{CH}_{4}\right)$ on gas pressure and coal and gas outbursts based on 
briquette specimens. Wang et al. [18] and Nie et al. [19] studied the evolution process and intensity of coal and gas outbursts, using briquettes for research. Additionally, using briquettes, Ding et al. [20] have discussed the influence of water content and gas pressure drop rate on coal and gas outbursts.

Obviously, the mechanical properties and structure of briquettes have a significant influence on outburst test results that cannot be ignored. The triaxial compression seepage characteristics of briquettes and raw tectonic coal specimens are quite different [21,22]. Skoczylas [23] found that porosity and other factors play an important role in the macroscopic mechanical properties and adsorption-desorption characteristics of briquettes. Yin Guangzhi et al. [24] compared the full stress-strain gas seepage characteristics of outburst coal and non-outburst coal. Xu Jiang et al. [25,26] investigated the effect of particle sizes on the coal and gas outburst characteristics and seepage characteristics of briquettes using different binders. Wang Kai et al. [27] investigated the effect of coal particle size on the dynamic characteristics of gas and pulverized coal using a self-developed pulverized coal-gas two-phase flow test system.

The difference between the test results based on briquettes and those based on raw tectonic coal is mainly attributed to meso-structure and coal particle size distribution. That is, particle size profoundly affects the mechanical properties of briquettes and the laboratory test results of coal and gas outbursts. While a large number of coal and gas outburst laboratory tests adopted briquettes, few systematic studies focused on the physical and mechanical properties of briquettes with different particle sizes and structural raw coal (unscreened structural coal specimens were retrieved on-site). This study aims to investigate the influence of coal particle size on the physical and mechanical properties of briquettes. Taking the coal and gas outburst characteristics of the Gaocheng coal mine as an example, a scientific grouping approach to briquette specimens with different particle sizes was proposed for testing. A series of uniaxial and triaxial tests of briquette specimens with different particle sizes were carried out, and the meso-failure mechanism of briquette specimens affected by particle sizes was discussed.

\section{Experimental Work}

\subsection{The Grouping Basis of Briquette Specimens with Different Particle Sizes}

The Gaocheng coal mine is a typical coal and gas outburst mine in Henan province, China (Figure 1a). The coal masses in this study were all collected from the longwall panel, 25091 (Figure 1b), in the Gaocheng coal mine No. II-1 coal seam of the Permian Shanxi group. The strength of the No. II-1 coal seam is very low. The coal masses are very loose due to gliding tectonics, and can be easily handcuffed. Therefore, it is difficult to take out a relatively intact coal block. The dimensions of the coal block are less than 5-10 cm, as shown in Figure 1c. There have been 15 coal and gas dynamic disasters caused by the loose coal structure since the mine was built, of which two were coal and gas outburst accidents.

It is necessary to investigate the particle size distribution characteristics of the outburst coal in the field in order to group the briquette specimens according to a particle size range before laboratory tests. Table 1 shows the particle size distribution of No. II- 1 coals. The sieving particle groupings were $>50,25-50,13-25,6-13,3-6,0.5-3$ and $<0.5 \mathrm{~mm}$, and the proportion of each sieve size was $1.95 \%$, $3.42 \%, 7.44 \%, 8.44 \%, 17.01 \%, 29.3 \%$ and $31.68 \%$, respectively. The results show that the smaller the particle size, the higher the proportion, and the largest proportion of pulverized coal was $<0.5 \mathrm{~mm}$. To retain the similarity of raw coal, the particle size distribution of briquette specimens should be in a range. Finally, three briquette specimen groups were determined according to particle size ranges of $2-6,0.18-0.25$ and $<0.11 \mathrm{~mm}$. 

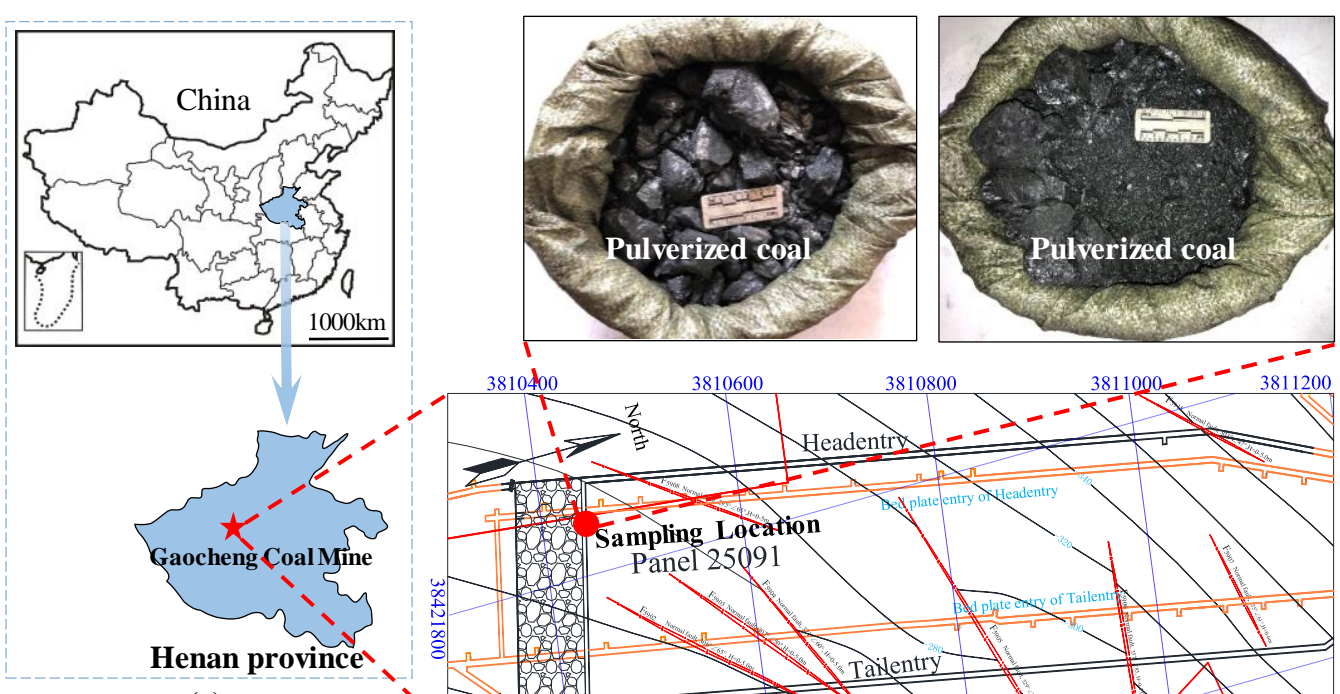

(c)

(a)

Figure 1. (a) The location of the Gaocheng coal mine; (b) the specific coal collection location in the Gaocheng coal mine; (c) the typical appearance of pulverized coal with an outburst property.

Table 1. The natural coal particle size distribution of the No. II-1 coal seam in the Gaocheng coal mine after screening.

\begin{tabular}{cccccccc}
\hline Particle Size (mm) & $\mathbf{> 5 0}$ & $\mathbf{2 5 - 5 0}$ & $\mathbf{1 3 - 2 5}$ & $\mathbf{6 - 1 3}$ & $\mathbf{3 - 6}$ & $\mathbf{0 . 5}-\mathbf{3}$ & $<\mathbf{0 . 5}$ \\
\hline Weight $(\mathrm{kg})$ & 194.41 & 343.62 & 746.93 & 847.12 & 1706.52 & 2983.01 & 3178.92 \\
Proportion $(\%)$ & 1.94 & 3.42 & 7.44 & 8.44 & 17.01 & 29.3 & 31.68 \\
\hline
\end{tabular}

\subsection{Briquette Specimen Preparation}

The microstructures and components of pulverized coal are vital for studying the physical and mechanical properties of briquette specimens. The microstructures of the pulverized coal samples were observed using a Merlin Compact field emission scanning electron microscope (Carl Zeiss, Oberkochen, Germany), with the results shown in Figure 2a,b. The scanning electron microscope (SEM) images show that the surfaces of the particles were further adhered to by tiny coal pieces and that there were voids between the particles. Micro-fractures and pores in the matrix could be seen clearly. Next, the associated mineral compositions of the pulverized coal samples were analyzed by a D8 ADVANCE X-ray diffractometer (Bruker AG, Karlsruhe, Germany), as shown in Figure 2c. There were two main minerals in the pulverized coal samples, birnessite and kaolinte, which had true densities of 4.33 and $2.63 \mathrm{t} / \mathrm{m}^{3}$. Obviously, the true densities of minerals in coal were much greater than the true densities of organic matter within coal. The average true density of minerals in coal was approximately $3.48 \mathrm{t} / \mathrm{m}^{3}$. Four types of pulverized coal with a coal particle size range of a natural distribution (Group A), 2-6 mm (Group B), $0.18-0.25 \mathrm{~mm}$ (Group C) and $<0.11 \mathrm{~mm}$ (Group D) were screened. The pulverized coal was mixed with a small amount of pure water and loaded into the molding abrasives. A molding pressure of $100 \mathrm{MPa}$ was maintained for 30 minutes. After demolding, the standard specimen with a diameter of $50 \mathrm{~mm}$ and height of $100 \mathrm{~mm}$ was made. The prepared coal specimen was dried at $105^{\circ} \mathrm{C}$ for $24 \mathrm{~h}$ and reserved a sealed box; this part of the briquette specimens is shown in Figure 2d. 

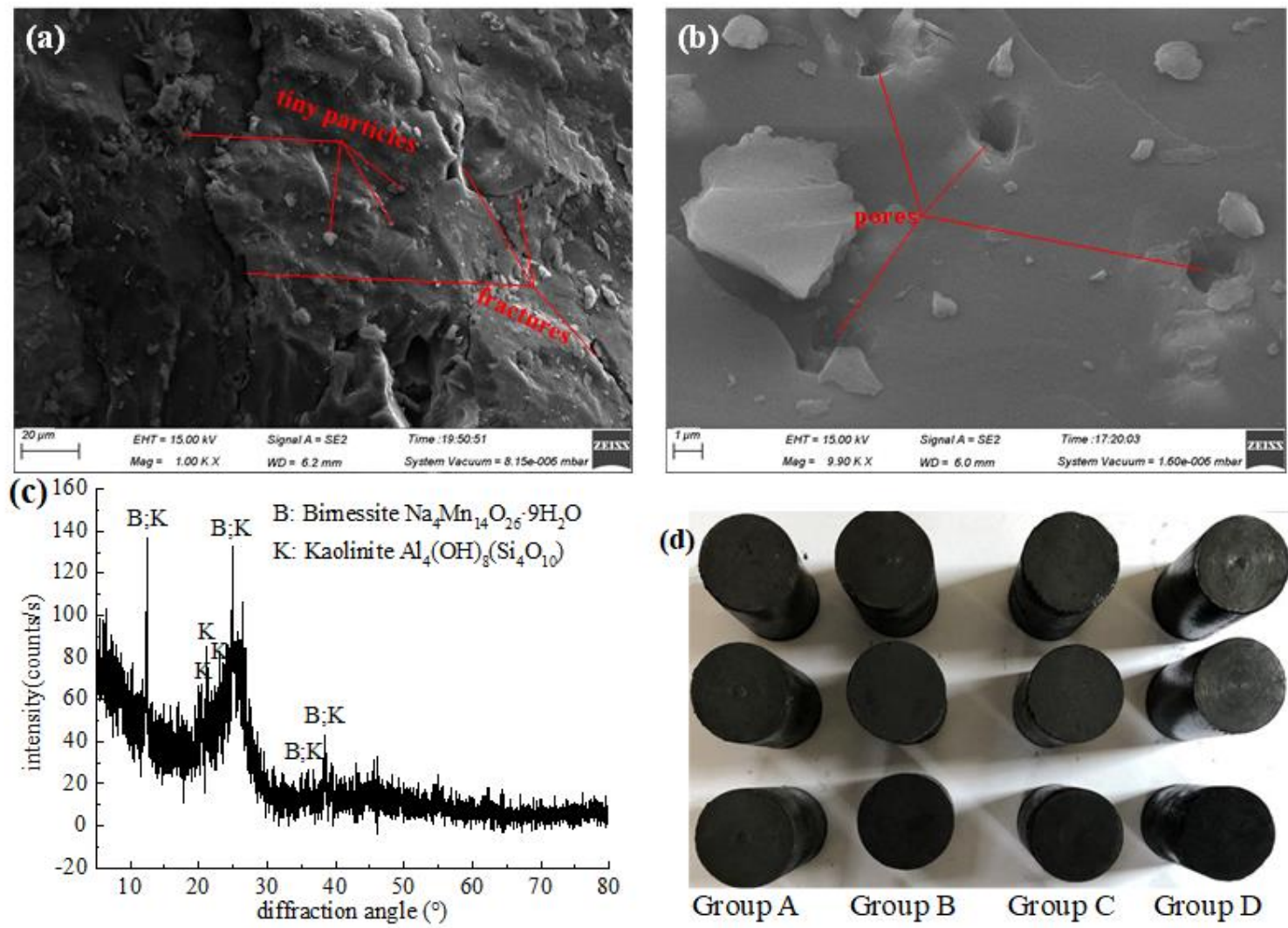

Figure 2. (a,b) Surface micromorphology of the pulverized coal; (c) X-ray diffraction pattern of pulverized coal; (d) part of the briquette specimens.

\subsection{Experimental Instrument and Measurement}

Uniaxial and triaxial compression tests were performed to evaluate the briquette specimens' mechanical properties. A rock mechanics testing-150B (RMT-150B) servo system was used to obtain the stress-strain data. The frame stiffness of the RMT-150B testing machine was $5.0 \times 10^{9} \mathrm{~N} / \mathrm{mm}$. The maximum axial load and confining pressure capacity were $1000 \mathrm{kN}$ and $50 \mathrm{MPa}$, respectively. Additionally, the loading rate used for this study was $0.01 \mathrm{~mm} / \mathrm{s}$.

\section{Results}

\subsection{Effect of Particle Size on Briquette Density}

The density of briquettes is closely related to the mechanical properties and microstructure of coal. The density of the briquette specimens was calculated by

$$
\rho=\frac{m}{V}
$$

where $\rho$ is the density of the briquette specimen; $m$ is the quality of the briquette specimen measured by the precision electronic scale (accuracy $0.01 \mathrm{~g}$ ) in $\mathrm{kg}$; and $V$ is the volume of the briquette specimen in $\mathrm{m}^{3}$.

The volume of the briquette specimen was calculated by

$$
V=\pi h \frac{d^{2}}{4}
$$

where $h$ is the height of the briquette specimen in $\mathrm{m}$; and $d$ is the diameter of the briquette specimen in $\mathrm{m}$. The $h$ and $d$ of the briquette specimen were measured using a digital caliper (accuracy: $0.01 \mathrm{~mm}$ ). 
The density of the coal sample can be calculated by Equations (1) and (2), as shown in Table 2. The true densities of minerals in coal are much greater than the true densities of organic matter within coal, and the higher the inorganic mineral content, the higher the true density of the coal [28]. Figure 3 shows the standard deviation of the density of different briquette specimens. As shown in Table 2 and Figure 3, the density of group A was relatively discrete, and the degree of dispersion decreased gradually as the coal particle size is decreased. The average densities of group A, B, C and D were $1275,1236.35,1181.64$ and $1159.81 \mathrm{~kg} / \mathrm{m}^{3}$, respectively, showing that density decreases as particle size decreases [29].

Table 2. The density of briquettes with different particle sizes $\left(\mathrm{kg} / \mathrm{m}^{3}\right)$.

\begin{tabular}{ccccc}
\hline No. & Group A & Group B & Group C & Group D \\
\hline 1 & 1322.20 & 1251.60 & 1177.35 & 1108.88 \\
2 & 1326.04 & 1224.75 & 1172.90 & 1159.19 \\
3 & 1261.27 & 1263.44 & 1175.54 & 1157.19 \\
4 & 1261.36 & 1226.50 & 1181.57 & 1167.38 \\
5 & 1210.10 & 1240.75 & 1180.20 & 1184.26 \\
6 & 1274.34 & 1234.53 & 1174.73 & 1155.40 \\
7 & 1218.36 & 1241.75 & 1174.04 & 1156.76 \\
8 & 1239.78 & 1261.75 & 1175.43 & 1157.85 \\
9 & 1217.14 & 1235.10 & 1221.93 & 1160.11 \\
10 & 1355.11 & 1194.79 & 1173.48 & 1162.26 \\
11 & 1304.74 & 1226.84 & 1182.29 & 1169.74 \\
12 & 1246.63 & 1237.41 & 1186.04 & 1165.89 \\
13 & 1337.97 & 1233.35 & 1185.76 & 1172.64 \\
$\bar{\rho}$ & 1275.00 & 1236.35 & 1181.64 & 1159.81 \\
\hline
\end{tabular}

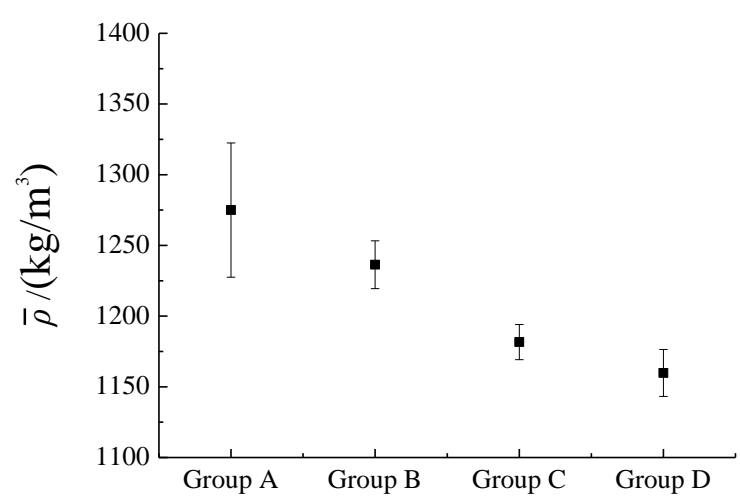

Figure 3. The density standard deviation of briquettes with different particle sizes.

\subsection{Effect of Particle Sizes on the Uniaxial Compression Test Results}

\subsubsection{Deformation Characteristics}

Table 3 and Figure 4 show the uniaxial compression test results for briquettes with different particle sizes. $R_{C}, E_{T}$ and $E_{50}$ are the uniaxial compressive strength, elastic modulus and deformation modulus, respectively. Elastic modulus $\left(E_{T}\right)$ refers to the slope of the approximate straight line segment with a peak strength range of $30-70 \%$ in the stress-strain curve, and deformation modulus $\left(E_{50}\right)$ is the ratio of $50 \%$ peak strength to the corresponding strain [30,31]. As shown in Table 3, the $R_{C}$ variation coefficients of the four groups were less than 0.3. Group $D$ had the highest $R_{C}$ variation, followed by group $A$, then group $B$ and, finally, group $C$, indicating that the dispersion of group $C$ was the smallest. 
Table 3. The uniaxial compression test results of briquettes with different particle sizes.

\begin{tabular}{ccccc}
\hline Group & No. & $R_{C} / \mathbf{M P a}$ & $E_{T} / \mathbf{M P a}$ & $E_{50} / \mathbf{M P a}$ \\
\hline \multirow{4}{*}{ A } & A-1 & 0.86 & 63 & 52 \\
& A-2 & 0.78 & 70 & 57 \\
& A-3 & 0.69 & 66 & 62 \\
& Mean & 0.77 & 66.33 & 57.00 \\
& Coefficient of variation & 0.11 & 0.05 & 0.09 \\
B & B-1 & 0.31 & 32 & 32 \\
& B-2 & 0.35 & 30 & 30 \\
& B-3 & 0.26 & 26 & 26 \\
& Mean & 0.31 & 29.33 & 29.33 \\
& Coefficient of variation & 0.15 & 0.10 & 0.10 \\
\hline \multirow{4}{*}{ C } & C-1 & 1.05 & 56 & 47 \\
& C-2 & 1.01 & 54 & 43 \\
& C-3 & 1.00 & 54 & 45 \\
& Coefficient of variation & 0.03 & 0.02 & 0.04 \\
\hline \multirow{2}{*}{ D } & D-1 & 1.57 & 79 & 62 \\
& D-2 & 1.57 & 79 & 64 \\
& D-3 & 1.90 & 127 & 96 \\
& Coefficient of variation & 1.68 & 95.00 & 74.00 \\
& & & 0.11 & 0.26 \\
\hline
\end{tabular}

As shown in Figure 4, the $R_{C}, E_{T}$ and $E_{50}$ of the briquette specimens showed an increasing trend as particle size decreased, with those of group $B$ representing the lowest. Compared with the $R_{C}$ of group B, that of group C and D increased by $229.03 \%$ and $441.94 \%$, respectively; the $E_{T}$ of group $C$ and D increased by $89.40 \%$ and $265.38 \%$, respectively; and the $E_{50}$ of group $C$ and $D$ increased by $53.43 \%$ and $152.30 \%$, respectively. Compared with group A, the $R_{C}$ of group B, C and D decreased by $59.74 \%$ and increased by $32.47 \%$ and $118.18 \%$, respectively, while the $E_{T}$ of group B decreased by $55.78 \%$ and $17.58 \%$ and increased by $43.22 \%$ respectively. The $E_{50}$ of group B, C and D decreased by $5.78 \%$ and $17.58 \%$ and increased by $43.22 \%$, respectively. The uniaxial compressive strength, elastic modulus and deformation modulus of group A were similar to those of group C.

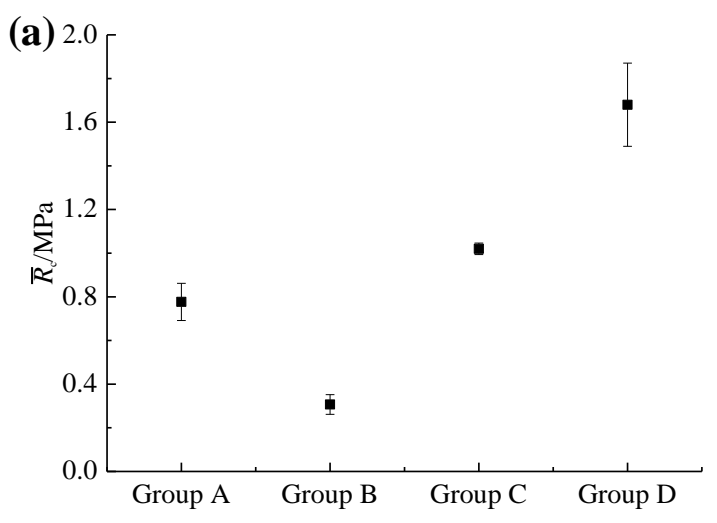

Figure 4. Cont. 

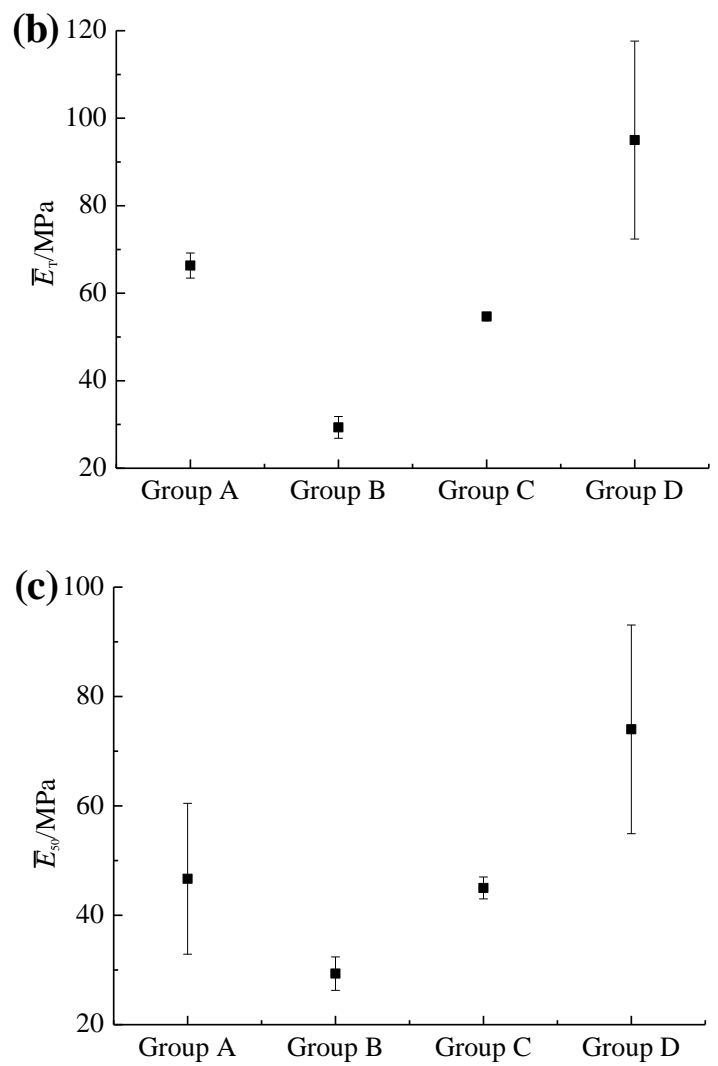

Figure 4. Variation of the uniaxial compression test result error bars with the coal particle size. (a) The relationship between uniaxial compressive strength and coal particle size; (b) the relationship between elastic modulus and coal particle size; and (c) the relationship between deformation modulus and coal particle size.

Figure 5 shows the stress-strain curves of the four groups during the uniaxial compression tests. As shown in Figure 5, the stress-strain curves had four stages: compaction, elasticity, yield and failure. The compression stage of group A was not obvious, the elastic stage and the plastic stage were obvious, the post-peak strength did not drop obviously and it was clear that there was a yield platform near the peak strength. The stress-strain curves of group B were similar to those of group A in the elastic and plastic stages, but the post-peak softening was more obvious. The elastic stage of group $C$ was obvious, the compaction stage and plastic stage were not obvious, the post-peak strength dropped obviously and the yield platform near the peak was not obvious, showing brittle characteristics. The elastic stage of group D was similar to that of group C, and the strength of group D showed an obvious step drop after the peak, showing brittle characteristics. The plastic characteristics of the briquette specimens showed a strong negative correlation with particle size. The deformation characteristics of briquette $\mathrm{A}$ were similar to those of briquette $\mathrm{B}$. 

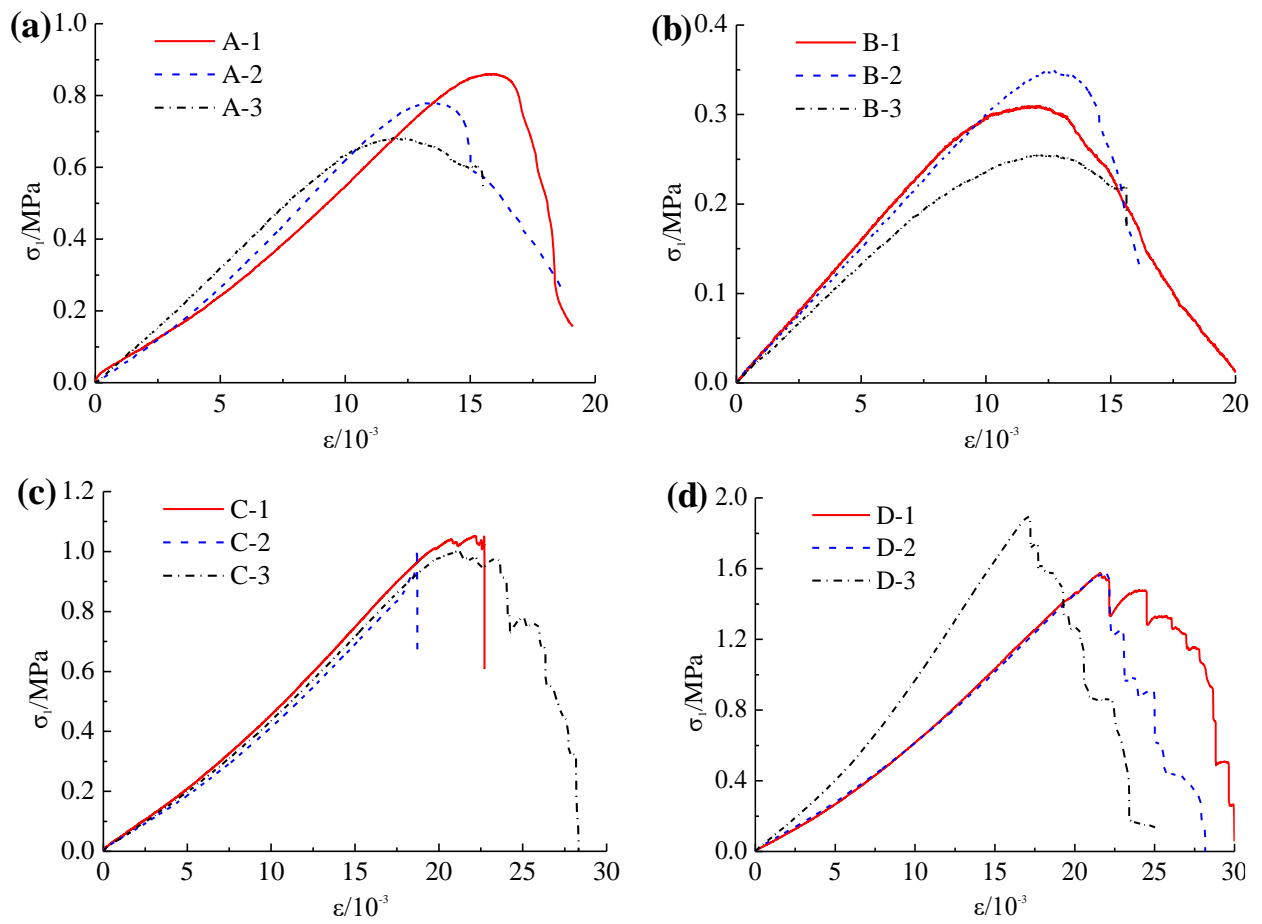

Figure 5. Stress-strain curves of the uniaxial compression of briquettes with different particle sizes:

(a) group A, (b) group B, (c) group C and (d) group D.

\subsubsection{Failure Morphology}

Figure 6 shows the failure mode of briquettes with different particle sizes after uniaxial compression. From Figure 6, it can be clearly seen that coal samples with fractures were damaged to varying degrees [31,32]. Group A and B were relatively complete on the whole, showing strong plastic deformation characteristics, but group $\mathrm{C}$ and $\mathrm{D}$ had a poor integrity with a large number of coal fragments along the fractures, especially group $\mathrm{D}$, which had more serious damage, showing strong brittle characteristics.
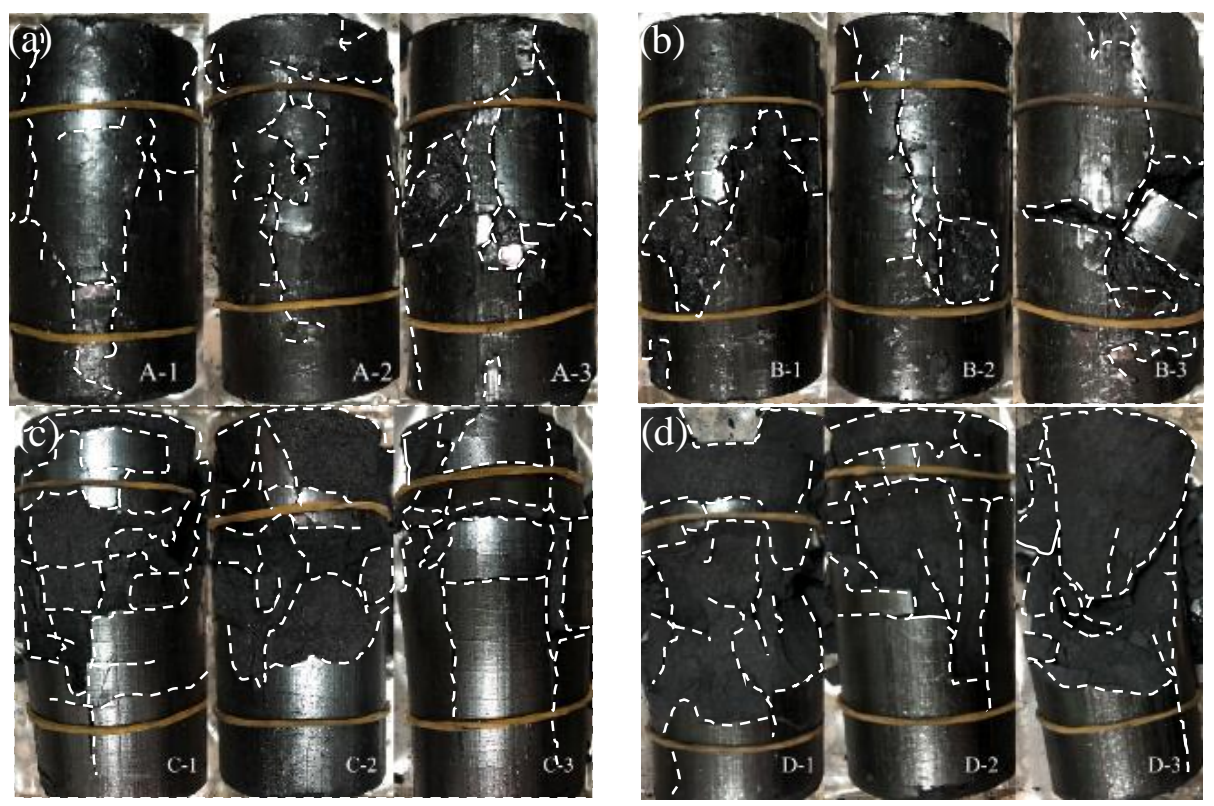

Figure 6. Uniaxial compression failure morphology of briquettes with different particle sizes: (a) group A, (b) group B, (c) group C and (d) group D. 


\subsection{Effect of Particle Size on the Triaxial Compression Test Results}

\subsubsection{Deformation Characteristics}

Table 4 shows the triaxial compression test results, with $\sigma_{3}, \sigma_{3-1}, \sigma_{1}, E_{\mathrm{T}}, \varepsilon_{0}$ and $\varepsilon_{1}$ being the designed confining pressure, actual confining pressure, peak strength, elastic modulus, strain corresponding to the peak strength and strain corresponding to a peak strength range of $70-100 \%$ in the stress-strain curve, respectively. Figure 7 shows the variations of $\sigma_{1}$, and $E_{\mathrm{T}}$ with particle size. As shown in Figure 7 , $\sigma_{1}$ and $E_{\mathrm{T}}$ with same particle size were positively correlated with the confining pressure. Under the same confining pressure, $\sigma_{1}$ increased as the particle size decreased. The $\sigma_{1}$ of group A was between that of group B and C.

Table 4. Triaxial test results of briquettes with different particle sizes.

\begin{tabular}{cccccccc}
\hline Group & No. & $\sigma_{3} / \mathbf{M P a}$ & $\sigma_{3-1} / \mathbf{M p a}$ & $\sigma_{\mathbf{1}} / \mathbf{M P a}$ & $E_{\mathbf{T}} / \mathbf{G P a}$ & $\varepsilon_{\mathbf{0}} / \mathbf{1 0}^{-3}$ & $\varepsilon_{\mathbf{1}} / \mathbf{1 0}^{-\mathbf{3}}$ \\
\hline \multirow{6}{*}{$\mathrm{A}$} & A-4 & 0.20 & 0.23 & 2.85 & 0.13 & 44.25 & 26.72 \\
& A-5 & 0.40 & 0.37 & 3.67 & 0.17 & 31.11 & 9.31 \\
& A-6 & 0.60 & 0.58 & 5.28 & 0.23 & 29.17 & 11.67 \\
& A-7 & 0.80 & 0.78 & 6.01 & 0.24 & 51.20 & 29.85 \\
& A-8 & 1.00 & 1.01 & 7.92 & 0.35 & 32.80 & 12.01 \\
\hline \multirow{6}{*}{ B } & B-4 & 0.20 & 0.17 & 2.04 & 0.10 & 39.39 & 22.54 \\
& B-5 & 0.40 & 0.42 & 3.49 & 0.13 & 40.95 & 18.86 \\
& B-6 & 0.60 & 0.61 & 4.95 & 0.19 & 38.83 & 15.98 \\
& B-7 & 1.00 & 0.98 & 6.61 & 0.29 & 51.01 & 35.79 \\
\hline \multirow{6}{*}{ C } & C-4 & 0.20 & 0.22 & 3.36 & 0.10 & 37.99 & 12.09 \\
& C-5 & 0.40 & 0.38 & 4.61 & 0.14 & 40.32 & 11.13 \\
& C-6 & 0.60 & 0.58 & 6.23 & 0.18 & 46.97 & 15.65 \\
& C-7 & 0.80 & 0.78 & 7.61 & 0.21 & 47.81 & 14.74 \\
& C-8 & 1.00 & 0.98 & 8.76 & 0.24 & 47.85 & 15.22 \\
\hline \multirow{6}{*}{ D } & D-4 & 0.20 & 0.17 & 4.06 & 0.15 & 31.41 & 9.34 \\
& D-5 & 0.40 & 0.38 & 5.68 & 0.16 & 47.60 & 15.46 \\
& D-6 & 0.60 & 0.58 & 6.81 & 0.20 & 41.80 & 12.56 \\
& D-7 & 0.80 & 0.78 & 8.55 & 0.31 & 31.62 & 9.53 \\
& D-8 & 1.00 & 1.01 & 10.14 & 0.25 & 52.62 & 17.11 \\
\hline
\end{tabular}
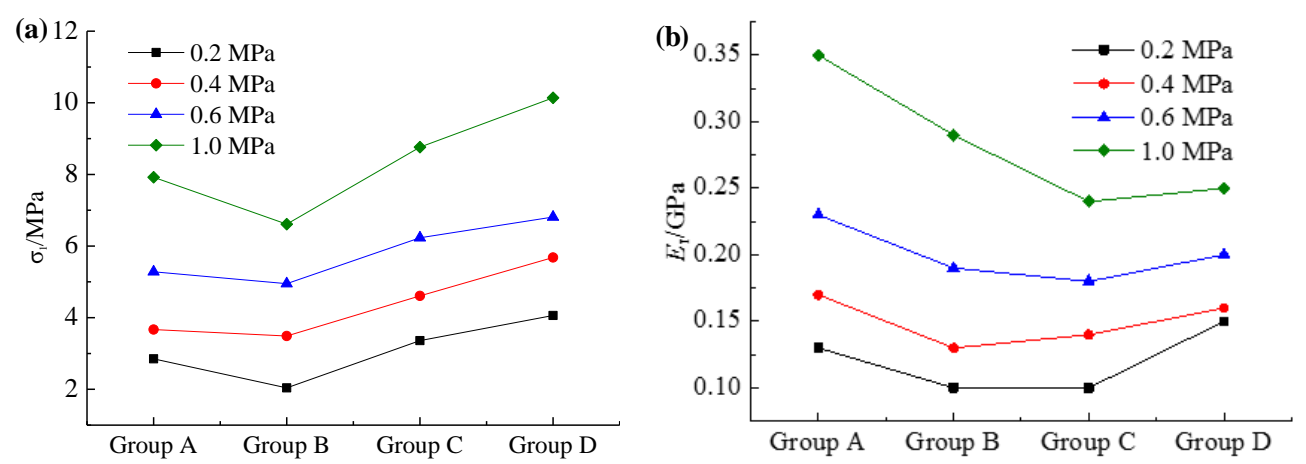

Figure 7. Test results concerning variations of triaxial compression with particle size: (a) peak strength and (b) elastic modulus.

Figure 8 shows the stress-strain curves of briquettes with different particle sizes under triaxial compression. The demarcation points between the elasticity and yield stages were not obvious for group A and B, and their bearing capacities remained constant near the peak values. Meanwhile, deformation increased continuously and the stress dropped slowly after the peak values, showing obvious plastic characteristics, especially in group B. For group C, the stress drop appeared after the peak at a low confining pressure, but it slowed down after the peak at a high confining pressure. Group 
D showed no obvious drop after the peak, except when the confining pressure was $1 \mathrm{MPa}$. Under other confining pressure conditions there were obvious post-peak stress-drop phenomena, showing brittle characteristics on the whole. In a word, the briquette specimens had strong plastic characteristics. The plastic properties of the briquette specimens of group B were the strongest, followed by those of group $C$ and then those of group D. The plastic properties were negatively correlated with particle size. The deformation characteristics of group A were between those of group B and C.
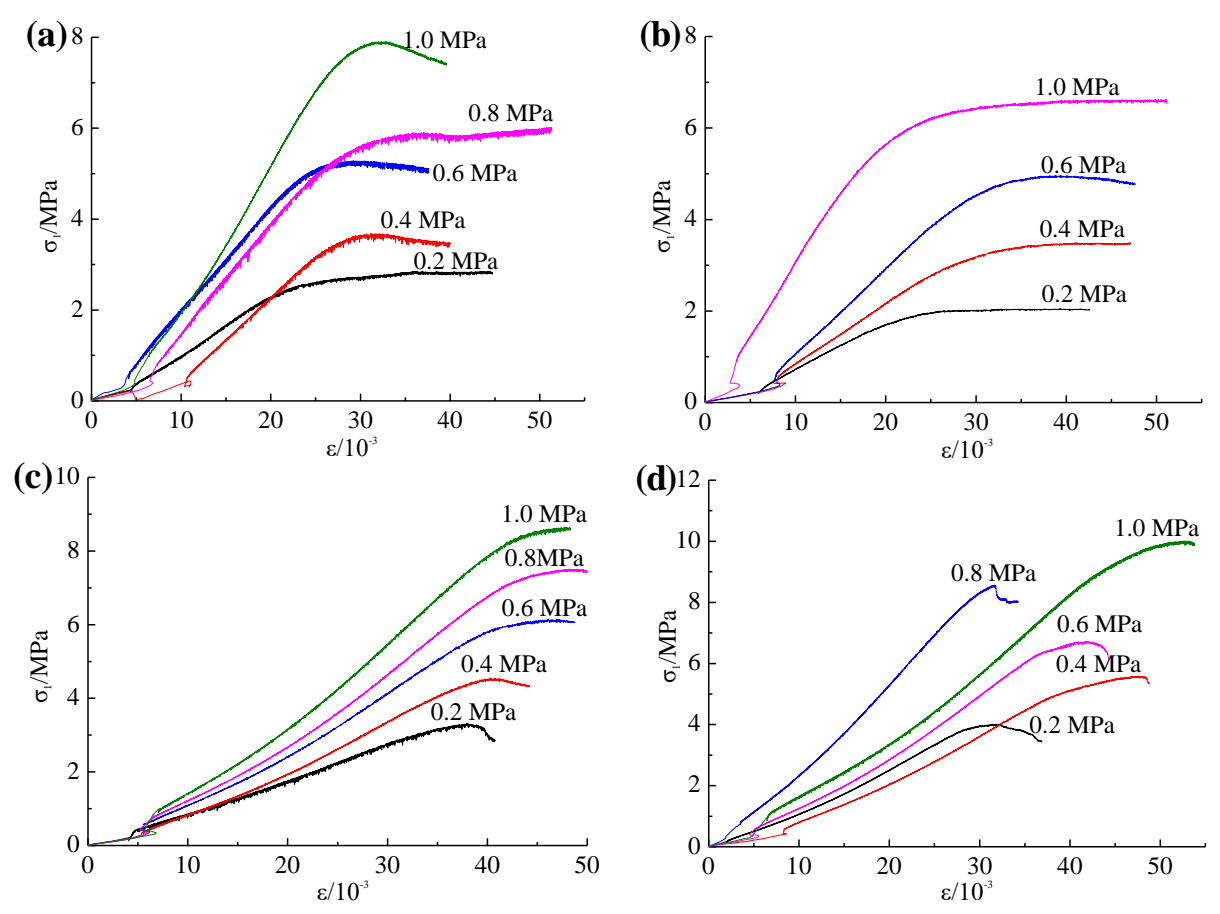

Figure 8. The triaxial compression stress-strain curves of briquettes with different particle sizes:

(a) group A, (b) group B, (c) group C and (d) group D.

\subsubsection{Strength Characteristics}

Figure 9 shows the relationship between the triaxial compression strength and confining pressure of briquettes with different particle sizes. It can be seen in Table 3 and Figure 9 that the triaxial compression strength of briquette specimens with different particle sizes increased approximately linearly with an increase of confining pressure, conforming to the Mohr-Coulomb strength criterion. Moreover, as the particle sizes decreased, the intercept values increased. Group B had the lowest slope and intercept values. The particle sizes played an important role in the strength of the coal, which had a critical influence on coal mine accidents.

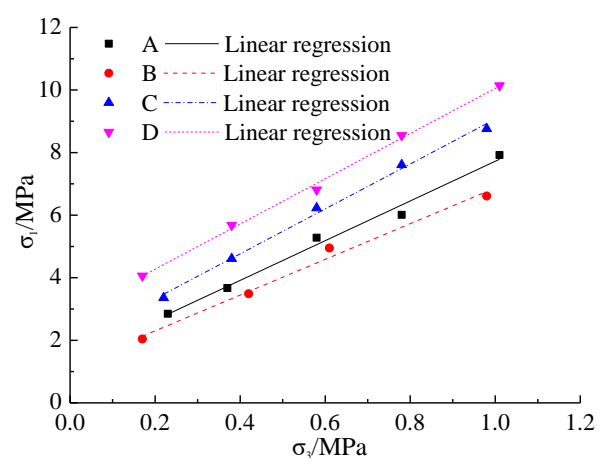

Figure 9. Variations of the triaxial compression strength with the confining pressure of briquettes of different particle sizes. 
According to the Mohr-Coulomb strength criterion:

$$
\sigma_{1}=K \sigma_{3}+Q
$$

where $Q$ and $K$ are the strength parameters. The relationship between them and the internal friction angle $\varphi$ and cohesion c are as follows:

$$
\begin{gathered}
\varphi=\arcsin \left(\frac{K-1}{K+1}\right) \\
c=\frac{Q(1-\sin \varphi)}{2 \cos \varphi}
\end{gathered}
$$

$K$ and $Q$ are shown in Table 5. As shown in Table 5, the confining pressure influence coefficient $(K)$ of group A was 6.35, while that of group B, C and D was 5.71, 7.18 and 7.23, respectively. $K$ increased as particle size decreased. According to the linear fitting results, the correlation coefficient of each group was greater than 0.95 , which indicates that the conventional triaxial compression strength under different particle sizes had a good linear correlation with the confining pressure.

Table 5. Linear fitting results for group A, B, C and D.

\begin{tabular}{cccc}
\hline Group & $\boldsymbol{K}$ & $\boldsymbol{Q}$ & $\boldsymbol{R}^{\mathbf{2}}$ (Correlation Coefficient) \\
\hline A & 6.35 & 1.38 & 0.972 \\
B & 5.71 & 1.16 & 0.965 \\
C & 7.18 & 1.90 & 0.994 \\
D & 7.23 & 2.83 & 0.996 \\
\hline
\end{tabular}

The $c$ and $\varphi$ of briquettes with different particle sizes are shown in Table 6 and Figure 10. Compared with group B, the $c$ of group C and group D increased by $25 \%$ and $83.33 \%$ respectively, and their $\varphi$ increased by $10.07 \%$ and $10.36 \%$, respectively. The $c$ and $\varphi$ of group A were $0.13 \mathrm{MPa}$ and $46.71^{\circ}$, respectively. Compared with group A, the $c$ of group B, C and D decreased by $7.79 \%$ and increased by $15.58 \%$ and $69.23 \%$, respectively, while the $\varphi$ of group B, C and D decreased by $4.56 \%$ and increased by $5.05 \%$ and $5.33 \%$, respectively. As the particle size decreased, $c$ and $\varphi$ showed an increasing trend. The $c$ of group A was between that of group B and C.

Table 6. Cohesion and internal friction angle of briquettes with different particle sizes.

\begin{tabular}{ccccc}
\hline Group & $c / \mathbf{M P a}$ & Variation of $c$ Based on Group A/\% & $\left.\boldsymbol{\varphi} / \mathbf{(}^{\circ}\right)$ & Variation of $\boldsymbol{\varphi}$ Based on Group A/\% \\
\hline A & 0.13 & N/A & 46.71 & N/A \\
B & 0.12 & -7.79 & 44.58 & -4.56 \\
C & 0.15 & 15.38 & 49.07 & 5.05 \\
D & 0.22 & 69.23 & 49.20 & 5.33 \\
\hline
\end{tabular}

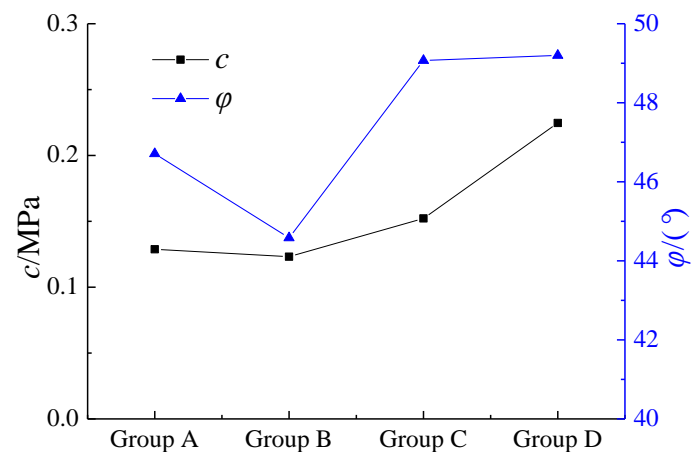

Figure 10. The cohesion and internal friction angle of each group. 
$Q$ in Equation (3) is the theoretical uniaxial compression strength calculated from the triaxial test results. It is the uniaxial compression shear strength. However, coal specimens under uniaxial compression do not constitute a single-shear failure; rather, most of them constitute a shear-tension composite failure, so their actual strength is usually lower than their theoretical strength. It is impossible to obtain $Q$ from a single specimen, and it should be calculated by a regression analysis of the triaxial compression strength of multiple specimens under different confining pressures $[30,33]$. The strength $Q$ of briquettes with different particle sizes is plotted in Figure 11a, and the relationship between plasticity and particle sizes in different groups can be seen in Figure $11 \mathrm{~b}$ in an indirect way.
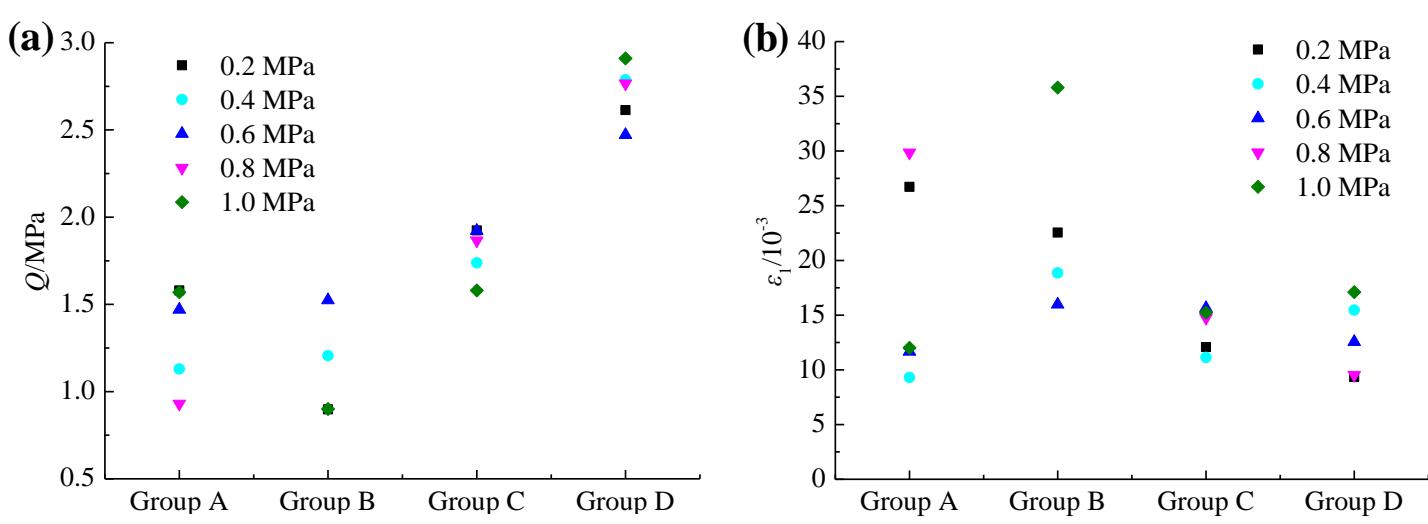

Figure 11. (a) The relationship between material strengths and different particle sizes; (b) the relationship of $\varepsilon_{1}$ and different particle sizes.

As seen in Figure 11a, the $Q$ of each group under different confining pressure conditions was somewhat discrete, especially for group $\mathrm{A}$ and $\mathrm{B}$, the $Q$ of which were close and relatively small. Under different confining pressures, $Q$ tended to increase as the particle size decreased. The $\varepsilon_{1}$ of the stress-strain curves was the plastic deformation stage [32,34]. The smaller $\varepsilon_{1}$ was, the higher the strength, and the worse the plasticity. The highest $\varepsilon_{1}$ of groups B, C and D decreased gradually, with the $Q$ increasing; in other words, the plasticity of groups B, C and D decreased (Figure 11). Meanwhile, the $\varepsilon_{1}$ of group $\mathrm{A}$ was discrete, with poor regularity.

\section{Discussion}

From the above results, it can be seen that the dispersion of the physical and mechanical properties of group A was stronger than that of the physical and mechanical properties of other groups. The mechanical strength of briquettes increased as particle size decreased, and the plastic properties increased with an increase in particle size. Therefore, the influence of the particle size of pulverized coal on the physical and mechanical properties of briquettes cannot be ignored.

The coal particle distribution maps of groups A, B, C and D were obtained by the Stereo Discovery V20 (Carl Zeiss, Germany), as shown in Figure 12.

From Figure 12, it can be seen that the coal particle distribution of each group is obviously different. The larger the particle size, the more macro-cracks the coal contains, the more irregular the contact between particles and the rougher the cross-sections are. As particle size decreases, the section becomes more regular and smoother. There are many kinds of forces between briquette particles, such as mechanical meshing force, chemical force, solid bridge bond and van der Waals force. The mechanical properties of briquette without binders mainly depend on the mechanical meshing force between particles. Usually, coal particles show simple stacking under the condition of no stress, and the contact between particles is mostly point contact, as shown in Figure 13a. There is a certain space between the coal particles, so that the coal particles can be crushed and fill the gap between the particles during the preparation process, as shown in Figure 13b. Before compaction, the particle skeleton makes it difficult for coal particles to form a strong bond, resulting in a "loose particle" distribution [35]. Under 
compaction, the internal cracks of coal particles are compressed, the contact of coal particles are closer (showing surface contact) and the particles can even be embedded within each other (Figure 13c). Under this condition, the phenomenon of shear self-locking occurs, which can form a strong mechanical meshing force.
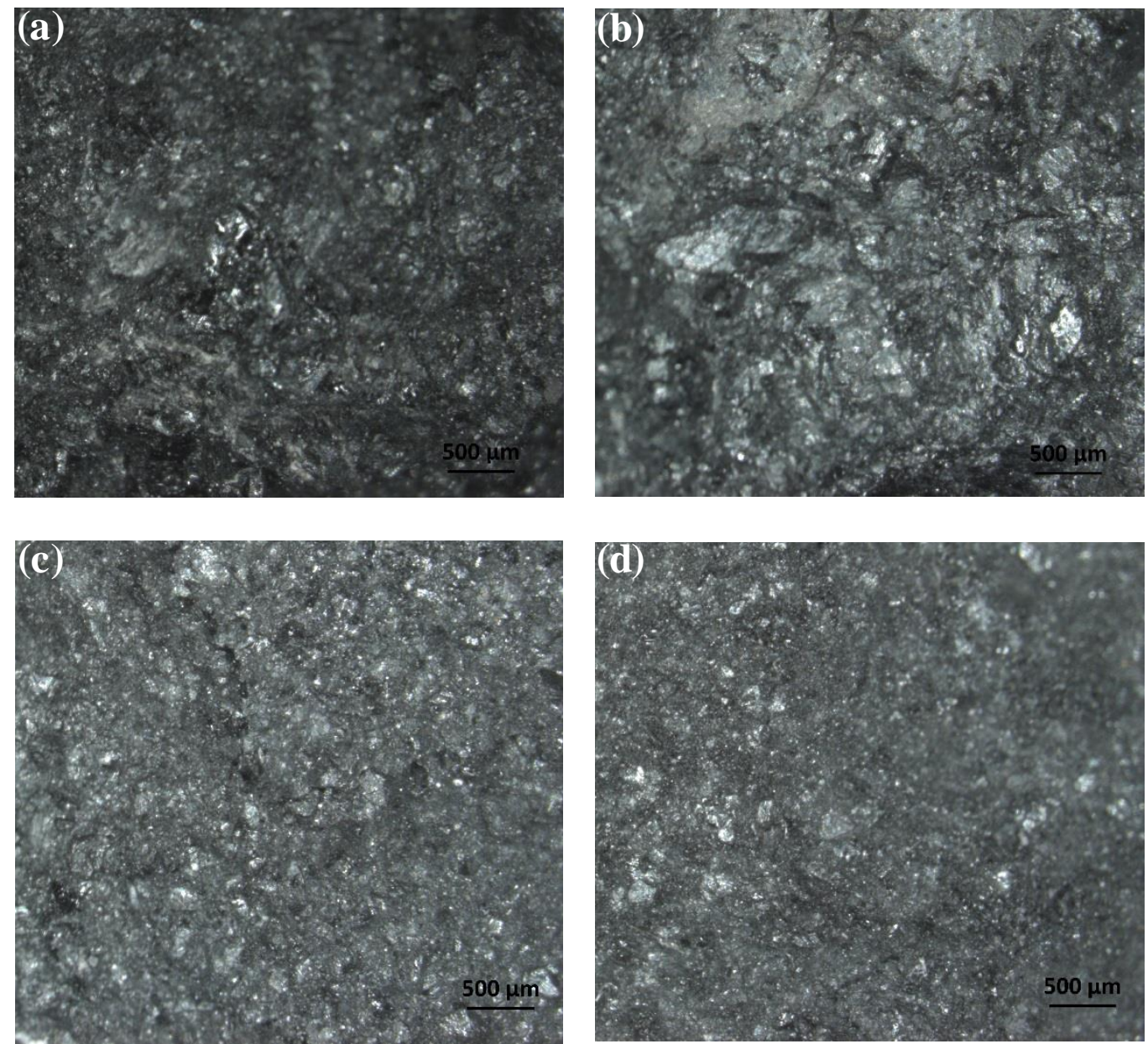

Figure 12. Sectional view of briquettes with different particle sizes: (a) group A, (b) group B, (c) group $\mathrm{C}$ and (d) group D.

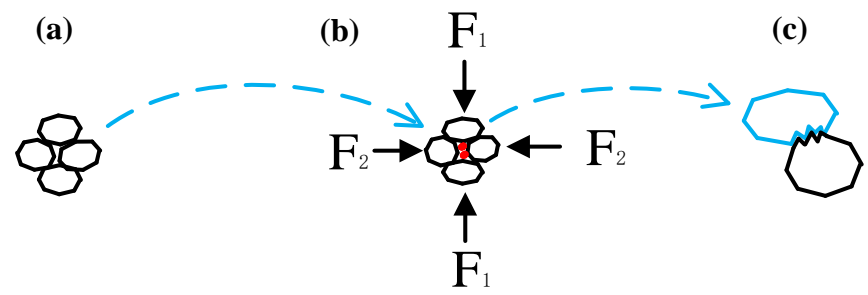

Figure 13. Schematic diagram of the molding process during briquetting. (a) Loosely packed particles, (b) particles formed under loading and (c) the interpenetration of particles.

Figure 14 is a schematic diagram of briquette failure under loading. When briquettes are subjected to external forces, there is a structural surface friction between particles (Figure 14a), structural wedge friction (Figure 14b), fragmentation along the fracture surface (Figure 14c) and compaction of loose particles (Figure 14d) between the coal particles. The failure mechanism of briquettes with different particle sizes is different. The structure of briquettes with different particle sizes is abstracted, as shown in Figure 15. The red part in the picture shows "loose particles". The volume fraction of loose particles 
decreases as particle size is decreased. When briquettes are loaded, loose particles will be compacted again, so the plastic characteristics of briquettes will be proportional to the volume of loose particles.<smiles>FC1CC(P)C(P)CC1P</smiles>

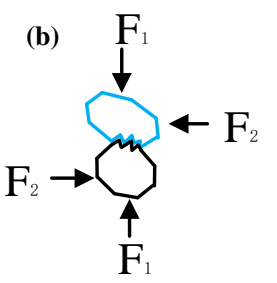

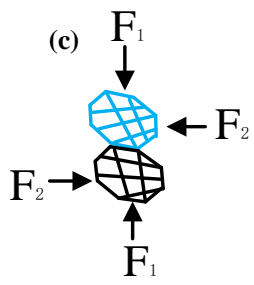<smiles>F[R](F)(F)F</smiles>

Figure 14. Schematic diagram of briquettes' failure mode under loading. (a) The structural surface friction between particles, (b) structural wedge friction, (c) fragmentation along the fracture surface and (d) compaction of loose particles.
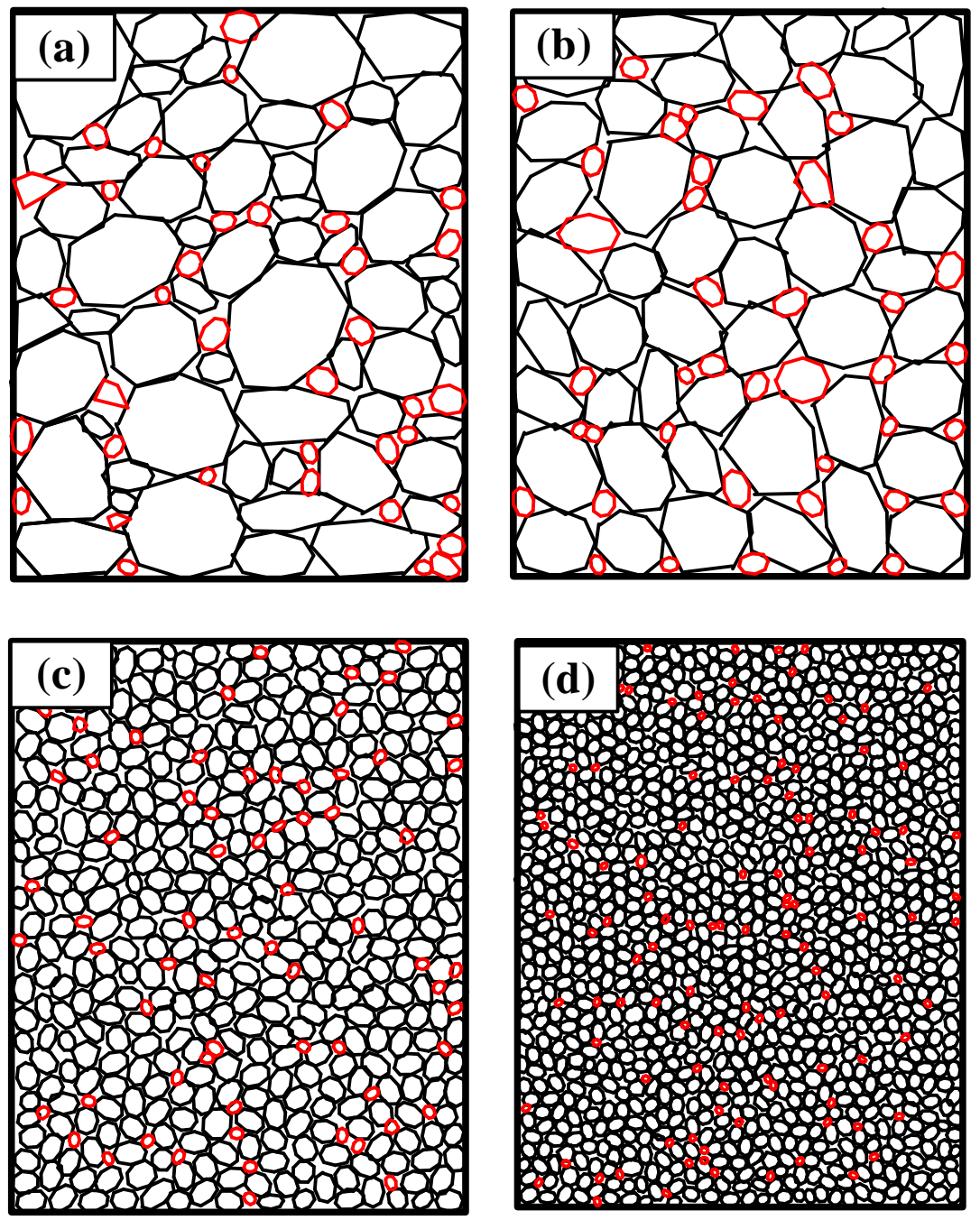

Figure 15. Abstract diagram of the structure of briquettes with different particle sizes: (a) group A, (b) group B, (c) group C and (d) group D.

Because group A contains many kinds of coal particles with different sizes, the gap between large particles is filled by small particles, and the cohesion between particles is closer, so the mechanical characteristics of group A are stronger than those of group B. In addition, with the decrease in coal particles, the specific surface area increases, the contact between coal particles becomes closer, the cohesion becomes stronger, there are fewer structural planes among coal particles and there is less 
damage along the structural planes. Therefore, the briquettes compacted by small particles show a higher mechanical meshing force and higher cohesion.

\section{Conclusions}

This study aimed to investigate the influence of coal particle size on the physical and mechanical properties of briquettes. Taking the coal and gas outburst characteristics of the Gaocheng coal mine as an example, a scientific grouping approach of briquette specimens with different particle sizes was proposed for testing. A series of uniaxial and triaxial tests using briquette specimens with different particle sizes were carried out, and the meso-failure mechanism of the briquette specimens affected by the particle size was discussed. According to the experimental results, the following conclusions are drawn:

(1) The uniaxial compressive strength, elastic modulus and deformation modulus of briquettes increase as particle size decreases. The difference in uniaxial compression strength, elastic modulus and deformation modulus between the briquettes made from natural raw coal and those with a particle size of $0.18-0.25 \mathrm{~mm}$ is the smallest.

(2) Under the triaxial load condition, the cohesion, internal friction angle and peak strength of briquette specimens increase as particle size decreases, while the plastic deformation capacity decreases and the regularity of the cohesion and peak strength are more obvious. The strength characteristics of briquettes made from natural tectonic raw coal are between those of briquettes with particle sizes of 2-6 $\mathrm{mm}$ and $0.18-0.25 \mathrm{~mm}$, and their plastic characteristics are significant.

(3) In the briquette preparation process, the loose particles in the voids between the coal particles are the main factors affecting the plastic characteristics of the briquette specimens, and their mechanical properties mainly depend on the mechanical meshing force between particles—-the smaller the particles, the greater the mechanical meshing force.

Author Contributions: Resources, and funding acquisition Y.Y. and L.W.; investigation, conceptualization, project administration and supervision, Y.Y., L.W. and L.P.; formal analysis and data curation, L.P., F.W. and H.M.; validation, writing-original draft, and writing-review \& editing L.P. We are grateful to the staff at the Gaocheng coal mine for their assistance during the on-site sampling.

Acknowledgments: This work was sponsored by the National Natural Science Foundation of China (Nos. 51674102 and 51874121), the key scientific and technological research plan of Henan Province, China (No. 182102310002), and the funding for special research funds for colleges and universities in Henan Province, China (NSFRF180104).

Conflicts of Interest: The authors declare no conflict of interest.

\section{References}

1. Cheng, Y.P.; Wang, L.; Zhang, X.L. Environmental impact of coal mine methane emissions and responding strategies in China. Int. J. Greenh. Gas Con. 2011, 5, 157-166. [CrossRef]

2. Wang, L.; Cheng, Y.P.; Wang, L.; Guo, P.K.; Li, W. Safety line method for the prediction of deep coal-seam gas pressure and its application in coal mines. Saf. Sci. 2011, 50, 523-529. [CrossRef]

3. Hodot, B.B. Outburst of Coal and Coalbed Gas (Chinese Translation); China Industry Press: Beijing, China, 1966.

4. Shepherd, J.; Rixon, L.K.; Griffiths, L. Outbursts and geological structures in coal mines: A review. Int. J. Rock Mech. Min. Sci. Geomech. Abstr. 1981, 18, 267-283. [CrossRef]

5. Singh, J.G. A mechanism of outbursts of coal and gas. Min. Sci. Technol. 1984, 1, 269-273. [CrossRef]

6. Beamish, B.B.; Crosdale, P.J. Instantaneous outbursts in underground coal mines: An overview and association with coal type. Int. J. Coal Geol. 1998, 35, 27-55. [CrossRef]

7. Beamish, B.B. Continuous gas monitoring for the assessment of outburst-proneness at a mining face. Int. J. Min. Geol. Eng. 1990, 8, 131-147. [CrossRef]

8. Wierzbicki, M.; Skoczylas, N. The outburst risk as a function of the methane capacity and firmness of a coal seam. Arch. Min. Sci. 2014, 59, 1023-1031. [CrossRef]

9. Jian, K.; Lei, D.J.; Fu, X.H.; Zhang, Y.G.; Li, H.L. Effect of an electrostatic field on gas adsorption and diffusion in tectonic coal. Int. J. Min. Sci. Technol. 2015, 25, 607-613. [CrossRef]

10. Sachsenhofer, R.F.; Privalov, V.A.; Panova, E.A. Basin evolution and coal geology of the Donets Basin (Ukraine, Russia): An overview. Int. J. Coal Geol. 2012, 89, 26-40. [CrossRef] 
11. Yuan, L. Key technology for modern mining in Huainan coal area. J. China Coal Soc. 2007, 32, 8-12.

12. Cao, Y.X.; Davis, A.; Liu, R.X.; Liu, X.W.; Zhang, Y.G. The influence of tectonic deformation on some geochemical properties of coals a possible indicator of outburst potential. Int. J. Coal Geol. 2003, 53, 69-79. [CrossRef]

13. Li, H.Y. Major and minor structural features of a bedding shear zone along a coal seam and related gas outburst, Pingdingshan coalfield, Northern China. Int. J. Coal Geol. 2001, 47, 101-113. [CrossRef]

14. Li, H.Y.; Ogawa, Y.; Shimada, S. Mechanism of methane flow through sheared coals and its role on methane recovery. Fuel 2003, 82, 1271-1279. [CrossRef]

15. Gamson, P.D.; Beamish, B.B.; Johnson, D.P. Coal microstructure and micropermeability and their effects on natural gas recovery. Fuel 1993, 72, 87-99. [CrossRef]

16. Sobczyk, J. The influence of sorption processes on gas stresses leading to the coal and gas outburst in the laboratory conditions. Fuel 2011, 90, 1018-1023. [CrossRef]

17. Sobczyk, J. A comparison of the influence of adsorbed gases on gas stresses leading to coal and gas outburst. Fuel 2014, 115, 288-294. [CrossRef]

18. Wang, C.J.; Yang, S.Q.; Yang, D.D.; Li, X.W.; Jiang, C.L. Experimental analysis of the intensity and evolution of coal and gas outbursts. Fuel 2018, 226, 252-262. [CrossRef]

19. Nie, B.S.; Ma, Y.K.; Meng, J.Q.; Hu, S.T. Middle scale simulation system of coal and gas outburst. Chin. J. Rock Mech. Eng. 2018, 37, 1218-1225.

20. Ding, Y.L.; Yue, Z.Q. An experimental investigation of the roles of water content and gas decompression rate for outburst in coal briquettes. Fuel 2018, 234, 1221-1228. [CrossRef]

21. Cao, S.G.; Li, Y.; Guo, P.; Bai, Y.J.; Liu, Y.B. Comparative research on permeability characteristics in complete stress-strain process of briquettes and coal samples. Chin. J. Rock Mech. Eng. 2010, 29, 899-906.

22. Yin, G.Z.; Wang, D.K.; Zhang, D.M.; Wang, W.Z. Test analysis of deformation characteristics and compressive strengths of two types of coal specimens containing gas. Chin. J. Rock Mech. Eng. 2009, 28, 410-417.

23. Skoczylas, N.; Dutka, B.; Sobczyk, J. Mechanical and gaseous properties of coal briquettes in terms of outburst risk. Fuel 2014, 134, 45-52. [CrossRef]

24. Yin, G.Z.; Jiang, C.B.; Li, X.Q.; Wang, W.Z.; Cai, B. An experimental study of gas permeabilities of outburst and nonoutburst coals under complete stress-strain process. Rock Soil Mech. 2011, 32, 1613-1619.

25. Xu, J.; Liu, D.; Peng, S.J.; Wu, X.; Lu, Q. Experimental research on influence of particle diameter on coal and gas outburst. Chin. J. Rock Mech. Eng. 2010, 29, 1231-1237.

26. Xu, J.; Ye, G.B.; Li, B.B.; Cao, J.; Zhang, M. Experimental study of mechanical and permeability characteristics of moulded coals with different binder ratios. Rock Soil Mech. 2015, 36, 104-110.

27. Wang, K.; Wang, L.; Du, F.; Zhang, X.; Lou, Z.; Xin, C.P.; Cui, X.Y. Influence of coal powder particle sizes on dynamic characteristics of coal and gas outburst. J. China Coal Soc. 2019, 44, 1369-1377.

28. Yang, X.P. Physical Mineral Processing; Metallurgical Industry Press: Beijing, China, 2014.

29. Zhang, C.H.; Zhang, N.; Pan, D.J.; Qian, D.Y.; An, Y.P.; Yuan, Y.X.; Xiang, Z.; Wang, Y. Experimental Study on Sensitivity of Porosity to Pressure and Particle Size in Loose Coal Media. Energies 2018, 11, 2274. [CrossRef]

30. You, M.Q. Effect of confining pressure on the Young's modulus of rock specimen. Chin. J. Rock Mech. Eng. 2003, 22, 53-60.

31. Su, C.D.; Guo, W.B.; Li, X.S. Experimental research on mechanical prosperities of coarse sandstone after high temperatures. Chin. J. Rock Mech. Eng. 2008, 27, 162-170.

32. Liu, X.S.; Tan, Y.L.; Ning, J.G.; Lu, Y.W.; Gu, Q.H. Mechanical properties and damage constitutive model of coal in coal-rock combined body. Int. J. Rock Mech. Min. 2018, 110, 140-150. [CrossRef]

33. Nasseri, M.H.B.; Rao, K.S.; Ramamurthy, T. Anisotropic strength and deformational behavior of Himalayan schists. Int. J. Rock Mech. Min. 2003, 40, 3-23. [CrossRef]

34. Evans, I.; Pomeroy, C. The Strength of Cubes of Coal in Uniaxial Compression, Mechanical Properties of Non-Mettalic Brittle Materials; Butterworths Scientific Publications: London, UK, 1958.

35. Potyondy, D.O.; Cundall, P.A. A bonded-particle model for rock. Int. J. Rock Mech. Min. 2004, 41, $1329-1364$. [CrossRef]

(C) 2019 by the authors. Licensee MDPI, Basel, Switzerland. This article is an open access article distributed under the terms and conditions of the Creative Commons Attribution (CC BY) license (http://creativecommons.org/licenses/by/4.0/). 